\title{
Understanding the Molecular and Functional Mechanisms that Underlie Pharamcogenomics-Based Therapy
}

\section{Byung Hak Ha${ }^{1}$ and Titus J Boggon ${ }^{1,2 *}$}

${ }^{1}$ Department of Pharmacology, Yale University School of Medicine, New Haven, USA

${ }^{2}$ Yale Cancer Center, Yale University School of Medicine, New Haven, USA

The era of astonishing amounts of sequencing data is upon us. Current sequencing efforts that aim to discover the mutation burden in cancer, or other diseases, result in vast quantities of information that present key indicators for disease prognostic and driving forces, including acquired point mutations, loss of heterozygosity, missense and nonsense mutations. The key determinant for how this information can be usefully applied is to understand which alterations between normal and diseased cells are 'driving' the condition. Therefore provision of a clear molecular and functional basis for disease acquisition and progression will prove to be essential for development of future therapies.

Current and ongoing sequencing efforts for cancer and other diseases result in significant amounts of data. For example, sequencing efforts for melanoma can result in the patient mutation burden ranging from tens to thousands of acquired, expressed, somatic point mutations [1]. This clearly raises the questions "What mutations are important?" and "How can these data be used to discover new genomic-based therapeutics?" In the case of melanoma, mutations in BRAF are associated with approximately $50 \%$ of cases and result in an activated protein $[2,3]$, a finding that proved to be the key insight towards development of a BRAF-targeted small molecule, PLX4032 (Vemurafenib) that is now in clinical use [4] and is a definitive advance in melanoma treatment [5]. There is, however, no other single mutated gene to account for the remaining $50 \%$ of melanoma cases. Instead, mutations in multiple genes including NRAS, KIT, MAP2K1 and TRRAP, and an exciting mutation that has been recently discovered in RAC1 [1], all seem to be associated with, and maybe drive the melanoma. Clear understanding of the function of these proteins, their normal regulation mechanisms, the effect of mutations on their regulation, and how mutations impact signaling pathways are all needed to provide a rational basis to develop targeted therapeutics.

There is a significant amount of information known for how RAC1, a small GTPase, is regulated, and what the downstream effector molecules are [6]. Even so, however, the direct consequences of the newly discovered Proline-29 mutation to Serine in melanoma were not known. The first hint that this mutation could impact the activity of RAC1 was the discovery, by structural mapping to previously determined RAC1 crystal structures, that Proline-29 is located on the Switch I loop, a region that is functionally critical for small GTPases (Figure 1). Using an array of biochemical, cell biological and X-ray crystallography techniques, combined with existing knowledge for this protein, we are beginning to understand the impact of the melanomaassociated P29S mutation [1]. Interestingly, RAC1 may act as a node, with acquired mutations observed both upstream and downstream [1]. Therefore, although a full understanding of the functional consequences of this mutation will take a significant effort, there is increasing evidence suggesting that the RAC1 signaling pathway may be important for a portion of melanomas. Whether the discovery of RAC1 mutations can translate into a pathway-specific therapy to treat melanoma is not yet clear, however, the already large amount of data accumulated to understand the role of dysregulated RAC1 indicates the enormity of the task ahead; to move from sequencing data to targeted therapies.

In the case of RAC1, structural mapping of the mutation provided clear rationale to guide further studies, and our crystallographic studies then discovered significant conformational differences between wildtype and mutated protein in a functionally important part of RAC1, again suggesting the importance of the P29S mutation. The structural studies provided rationale, initial insights to potential importance, and aided hypothesis generation. Indeed, we find that mapping of recurrent acquired mutations to previously determined crystal structures, or homologous neighbours, can frequently aid the process of understanding the acquired mutations, can facilitate hypothesis generation, and can help triage these vast amounts of data. This can be especially useful when mutations occur in clear functionally important regions of an enzyme or signaling protein, for example the Switch

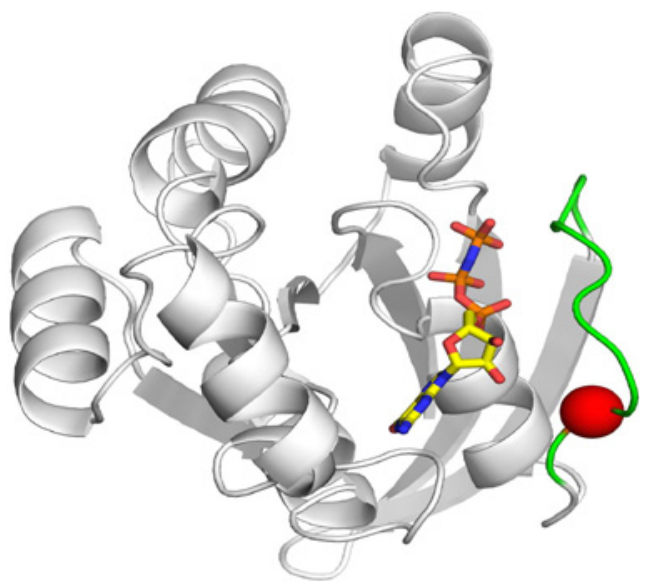

Figure 1: Structure of RAC1 indicating the location of the P29S mutation. Crystal structure of wild-type RAC1 is shown with GTP analogue, GMP-PNP shown in stick format, the Switch I loop colored green and Proline-29 shown as a sphere in red. PDB ID: 3TH5

*Corresponding author: Titus $\mathrm{J}$ Boggon, Department of Pharmacology and The Yale Cancer Center, Yale University School of Medicine, SHM B-316A, 333 Cedar Street, New Haven, CT 06520, USA, Tel: 203-785-2943; Fax: 203-785 5494; E-mail: titus.boggon@yale.edu

Received July 29, 2012; Accepted August 10, 2012; Published August 18, 2012

Citation: $\mathrm{Ha} \mathrm{BH}$, Boggon TJ (2012) Understanding the Molecular and Functional Mechanisms that Underlie Pharamcogenomics-Based Therapy. J Pharmacogenom Pharmacoproteomics 3: e122. doi:10.4172/2153-0645.1000e122

Copyright: (C) $2012 \mathrm{Ha} \mathrm{BH}$, et al. This is an open-access article distributed unde the terms of the Creative Commons Attribution License, which permits unrestricted use, distribution, and reproduction in any medium, provided the original author and source are credited. 
Citation: Ha BH, Boggon TJ (2012) Understanding the Molecular and Functional Mechanisms that Underlie Pharamcogenomics-Based Therapy. J Pharmacogenom Pharmacoproteomics 3:e122. doi:10.4172/2153-0645.1000e122

Page 2 of 2

regions of a GTPase (e.g. RAC1[1]), the activation loop of a kinase (e.g. EGFR [7]), or other known enzyme regulatory regions [8-14]. Furthermore, structural mapping can allow hypothesis generation for the effects of post-translational modification discovered by proteomic techniques $[15,16]$. The use of structural biology techniques in this way can sometimes provide the desired clear molecular and functional basis for altered activity, a key step in moving towards a Pharmacogenomicsbased therapy. Therefore, as this era of extremely large databases of disease-associated mutations rapidly encompasses us, there is increasing importance and relevance for the tools of the structural biologist to facilitate rapid transition from sequencing to targeted therapeutics.

\section{References}

1. Krauthammer M, Kong $\mathrm{Y}, \mathrm{Ha} B \mathrm{BH}$, Evans $\mathrm{P}$, Bacchiocci $\mathrm{A}$, et al. (2012) Exome sequencing identifies recurrent somatic RAC1 mutations in melanoma. Nat Genet (In the press)

2. Davies H, Bignell GR, Cox C, Stephens P, Edkins S, et al. (2002) Mutations of the BRAF gene in human cancer. Nature 417: 949-954.

3. Wan PT, Garnett MJ, Roe SM, Lee S, Niculescu-Duvaz D, et al. (2004) Mechanism of activation of the RAF-ERK signaling pathway by oncogenic mutations of B-RAF. Cell 116: 855-867.

4. Bollag G, Hirth P, Tsai J, Zhang J, Ibrahim PN, et al. (2010) Clinical efficacy of a RAF inhibitor needs broad target blockade in BRAF-mutant melanoma. Nature 467: 596-599.

5. Chapman PB, Hauschild A, Robert C, Haanen JB, Ascierto P, et al. (2011) Improved survival with vemurafenib in melanoma with BRAF V600E mutation. N Engl J Med 364: 2507-2516.

6. Rathinam R, Berrier A, Alahari SK (2011) Role of Rho GTPases and their regulators in cancer progression. Front Biosci 16: 2561-2571.

7. Paez JG, Janne PA, Lee JC, Tracy S, Greulich H, et al. (2004) EGFR mutations in lung cancer: correlation with clinical response to gefitinib therapy. Science 304: 1497-1500.

8. Meshinchi S, Stirewalt DL, Alonzo TA, Boggon TJ, Gerbing RB, et al. (2008) Structural and numerical variation of FLT3/ITD in pediatric AML. Blood 111 4930-4933.

9. Frohling S, Scholl C, Levine RL, Loriaux M, Boggon TJ, et al. (2007) Identification of driver and passenger mutations of FLT3 by high-throughput DNA sequence analysis and functional assessment of candidate alleles. Cancer Cell 12: 501-513

10. Costa DB, Halmos B, Kumar A, Schumer ST, Huberman MS, et al. (2007) BIM mediates EGFR tyrosine kinase inhibitor-induced apoptosis in lung cancers with oncogenic EGFR mutations. PLoS Med 4: 1669-1680.

11. Walters DK, Mercher T, Gu TL, O'Hare T, Tyner JW, et al. (2006) Activating alleles of JAK3 in acute megakaryoblastic leukemia. Cancer Cell 10: 65-75.

12. Mercher T, Wernig G, Moore SA, Levine RL, Gu TL, et al. (2006) JAK2T875N is a novel activating mutation that results in myeloproliferative disease with features of megakaryoblastic leukemia in a murine bone marrow transplantation model. Blood 108: 2770-2779.

13. Jiang J, Paez JG, Lee JC, Bo R, Stone RM, et al. (2004) Identifying and characterizing a novel activating mutation of the FLT3 tyrosine kinase in AML. Blood 104: 1855-1858.

14. Leidner RS, Fu P, Clifford B, Hamdan A, Jin C, et al. (2009) Genetic abnormalities of the EGFR pathway in African American Patients with nonsmall-cell lung cancer. J Clin Oncol 27: 5620-5626.

15. Kang S, Elf S, Dong S, Hitosugi T, Lythgoe K, et al. (2009) Fibroblast growth factor receptor 3 associates with and tyrosine phosphorylates p90 RSK2, leading to RSK2 activation that mediates hematopoietic transformation. Mol Cell Biol 29: 2105-2117.

16. Hitosugi T, Kang S, Vander Heiden MG, Chung TW, Elf S, et al. (2009) Tyrosine phosphorylation inhibits PKM2 to promote the Warburg effect and tumor growth. Sci Signal 2: 73. 